\title{
A Survey on The Roles of Life Style and Its Modification in The Prevention and Management of Cancer, Diabetes, Blood Pressure and Stroke
}

\author{
Paul SH, Usman AA, Auta M, Gana IN, Idemudia GE and Olutoye MA* \\ Department of Chemical Engineering, Federal University of Technology Minna, Nigeria
}

Submission: February 26, 2018; Published: October 11, 2018

*Corresponding author: Olutoye MA, Department of Chemical Engineering, Federal University of Technology Minna, Nigeria, Email: habilapaul@gmail.com

\begin{abstract}
A research titled "Formulation Of A Multifunctional Flora Composite And The Roles Of Life Style In The Prevention And Management Of Cancer, Diabetes, Blood Pressure And Stroke" was carried out using seven medicinal plants namely: Zingiber officinale (ginger), Curcuma longa (turmeric), Carica papaya (pawpaw), Vernonia amygdalina (bitter leave), Ocimum gratissimum (scent leaves), Psidium guajava (guava) and moringa oleifera (moringa) and a survey method of data collection on four basic diseases' risks factors they are: cancer, diabetes, blood pressure and stroke. The research was aimed at developing a multipurpose supplement from the above listed plants with its natural content and form unaltered. That is, to double as a food and a drug; performing bioactive functions and playing nutritional roles thus balancing the human body chemistry. It also studied the roles of life style and its modifications in the causes, prevention and management of cancer, diabetes, blood pressure and stroke. At the end of the research, the results of the survey on the life style dependent risks factors of cancer, diabetes, blood pressure and stroke, shows that the more one is predisposed or exposed to those risk factors (RFs), the greater the chance of becoming a victim of those diseases while maintaining a healthy life style or early adjustment to good healthy living or health conditions, will reduce the risks to the barest minimum.
\end{abstract}

The survey results based on the answers to the questionnaires, victims experiences and testimonies, also indicated that Adjustment of life style after effective treatment of the condition, greatly limit the chance of reoccurrence of the disease and one is able to live a decent and healthy life without using drugs. A cross examination of the risks factors shows that obesity or overweight and inactivity, are a major and common risks factors that leads to those diseases. Hence, no matter the type of treatment given, if life style is not adjusted, there was no reasonable improvement and in rare cases were one improves, the disease reoccurs worse than before. Hence the best drug to these diseases according to victims' experiences and responses is to adjust and maintain a healthy life style Irrespective of age, sex, origin and or race.

Keywords: Life Style; Modification; Cancer; Diabetes; Blood Pressure; Stroke; Prevention and Management

\section{Introduction}

Industrialization has led to many modifications in the lifestyle of the world's population, giving rise to increase in the indices of several diseases, including chronic degenerative diseases such as insulin resistance diabetes mellitus, blood pressure, Cancer, malaria fever, typhoid fever, kidney diseases, metabolic syndrome and other related cardiovascular diseases with overall effects that are capable of reducing the quality of life and increasing the costs of living; hospitalizations and medications of the people (Adesuyi AO et al. 2012). Many studies have shown that green plants and their extracts, either isolated or crudes, are very helpful in the prevention, management or treatment of such diseases as listed above and many more not mention depending on the types of source plants, methods of preparation and components of interest and their functions [1]. The bioactive compounds extracted from the source plants such as, Psidium guajava leaves and fruits, scent leaves, bitter leaves, moringa leaves, turmeric,
Ginger rhizomes and pawpaw leaves, contain very important, effective and excellent health beneficial bioactive compounds responsible for: hepatoprotection, antioxidant, anti-inflammatory, antispasmodic, anti-cancer, antimicrobial, anti-hyperglycaemic, analgesic, endothelial progenitor cells, anti-stomach-aches and anti-diarrhoea functions in each or most of them and form the constituents and composition of the scholarly multifunctional hybrid flora composite newly formulated which can be used for the treatment, prevention and management of diabetes, blood pressure, kidney stone, Cancer, malaria and typhoid fever (Adesuyi AO et al. 2012).

Roles of life style in the prevention and management of cancer, diabetes, blood pressure and stroke: Non-communicable diseases, which are also called chronic diseases, include diabetes, blood pressure and stroke, most forms of cancers and injuries. Such non-communicable diseases mainly result from abnormal 


\section{Current Research in Diabetes \& Obesity Journal}

life lifestyle and related factors such as unhealthy diet, lack of physical activity and the abuse of food and drugs like tobacco, alcohols and obesity [2]. Changes in lifestyles, behavioural patterns, demographic profile (aging population), socio-cultural and technological advancements are the leading factors to sharp increase in the prevalence of non-communicable disease [3]. These diseases by and large can be prevented by making simple changes modifications in the way humans live their lives or in a concise language; y by changing our lifestyles. Diabetes which is known to be a major risk factor for the emergence of chronic diseases on its own causes increased death and disability in our society Nigeria. Development of diabetes and heart attacks at an early age is largely because of environmental causes such as low consumption of fresh fruits and vegetables along with other unhealthy diet, increasing use of tobacco, and higher prevalence of sedentary life-style (ASH, 2010). Coronary artery disease (CAD), ischemic stroke, diabetes, and some specific cancers, which until recently were common only in high-income countries, are now becoming the dominant sources of morbidity and mortality worldwide [4].

In addition, rates of cancers and cardiovascular disease (CVD) among migrants from low-risk to high-risk countries almost always increase dramatically (B.P.A.U.K.C, 2008). In traditional African societies, for example, CAD is virtually nonexistent, but rates among African Americans are similar to those among Caucasian Americans. These striking changes in rates within countries over time and among migrating populations indicate that the primary determinants of these diseases are not genetic but environmental factors, including diet and lifestyle [5].

Thus, considerable research has been aimed at identifying modifiable determinants of chronic diseases [6]. Prospective epidemiological studies, some randomized prevention trials, and many short-term studies of intermediate endpoints such as blood pressure and lipids have revealed a good deal about the specific dietary and lifestyle determinants of major chronic diseases [7]. A general conclusion is that reducing identified, modifiable dietary and lifestyle risk factors could prevent most cases of CAD, stroke, diabetes, and many cancers among high-income populations these findings are profoundly important, because they indicate that these diseases are not inevitable primarily as the consequence of a modern society [8]. Furthermore, low rates of these diseases can be attained without drugs or expensive medical facilities, an outcome that is not surprising, because their rates have historically been extremely low in developing countries with few medical facilities. However, preventing these diseases will require changes in behaviours relating to smoking, alcoholism, obesity, other physical activity, and or diets (I.C.S.S.Q.; 2013).

These life styles changes are: Avoiding Tobacco Use, Avoidance of smoking by preventing initiation or by cessation for those who already smoke is the single most important way to prevent CVD and cancer. Avoiding the use of smokeless tobacco will also prevent a good deal of oral cancer (I.N.D.N.; 2013). Maintain a Healthy Weight: Obesity is increasing rapidly worldwide which leads to such conditions. Even though obesity a body mass index (BMI) of 30 or greater has received more attention than overweight, overweight (BMI of 25 to 30) is typically even more prevalent and also indicates elevated risks of many diseases. For example, overweight people experience a two- to threefold elevation in the risks of CAD and hypertension and a more than tenfold increase in the risk of type 2 diabetes compared with lean individuals (BMI less than 23) [9]. Both overweight and obese people also experience elevated mortality from cancers of the colon, breast (postmenopausal), kidney, endometrium, and other sites cancers. Body mass index (BMI) this is an approximate measure of whether someone is over- or underweight, calculated by dividing their weight in kilograms by the square of their height in metres [3].

For most people, unless obviously malnourished as an adolescent or young adult, bodyweight should ideally not increase by more than 2 or 3 kilograms after age 20 to maintain optimal health. Thus, a desirable weight for most people should be within the BMI range of 18.5 to 25.0 , and preferably less than 23. In many studies, waist circumference is a strong predictor of CAD, stroke, and type 2 diabetes, even after controlling for BMI. A waist circumference of approximately 100 centimetres for men and 88 centimetres for women has been used as the criterion for the upper limit of the healthy range in the United States, but for many people this extent of abdominal fat would be far above optimal. Because abdominal circumference is easily assessed, even where scales may not be available, further work to formulate locally appropriate criteria could be worthwhile [10]. In the meantime, increases of more than 5 centimetres can be used as a basis for recommending immediate changes in life style (activity patterns and diet) [2]. Maintain Daily Physical Activity and Limit seating in one place for a long time: Contemporary life in developed nations has markedly reduced people's opportunities to expend energy, whether in moving from place to place, in the work environment, or at home.

Dramatic reductions in physical activity are also occurring in developing countries because of urbanization, increased availability of motorized transportation to replace walking and bicycle riding, and mechanization of labour. However, regular physical activity is a key element in weight control and prevention of obesity). For example, among middle-aged West African women, more walking was associated with a three-unit lower BMI), and in China, car owners are 80 percent more likely to be obese [7]. In addition to its key role in maintaining a healthy weight, regular physical activity reduces the risk of CAD, stroke, type 2 diabetes, colon and breast cancer, osteoporotic fractures, osteoarthritis, depression, and erectile dysfunction. Important health benefits have even been associated with walking for half an hour per day, but greater reductions in risk are seen with longer durations of physical activity and more intense activity (Mathangi S.M. R, and Shaker A.M, 2015).

Eat a Healthy Diet: Medical experts have long recognized the effects of diet on the risk of CVD, but the relationship between diet and many other conditions, including specific cancers, diabetes, cataracts, macular degeneration, cholelithiasis, renal stones, dental disease, and birth defects, have been documented more re- 


\section{Current Research in Diabetes \& Obesity Journal}

cently [11]. These goals are consistent with a detailed 2013 World Health Organization (WHO) report (Replace saturated and Trans fats with unsaturated fats, including sources of omega-3 fatty acids. Replacing saturated fats with unsaturated fats will reduce the risk of CVD by reducing serum low-density lipoprotein (LDL) cholesterol. Also, polyunsaturated fats (including the long-chain omega-3 fish oils and probably alpha-linoleic acid, the primary plant omega-3 fatty acid) can prevent ventricular arrhythmias and thereby reduce fatal CAD [12]. In a case-control study in Costa Rica, where fish intake was extremely low, the risk of myocardial infarction was 80 percent lower in those with the highest alpha-linoleic acid intake. Intakes of omega- 3 fatty acids are suboptimal in many populations, particularly if fish intake is low and the primary oils consumed are low in omega- 3 fatty acids (for example, partially hydrogenated soybean, corn, sunflower, or palm oil). These findings have major implications, because changes in the type of oil used for food preparation are often quite feasible and not ensure generous consumption of fruits and vegetables and adequate folic acid intake [13].

Strong evidence indicates that high intakes of fruits and vegetables will reduce the risk of CAD and stroke Some of this benefit is mediated by higher intakes of potassium, but folic acid probably also plays a role Supplementation with folic acid reduces the risk of neural tube defect pregnancies [12]. Substantial evidence also suggests that low folic acid intake is associated with greater risk of colon and possibly breast cancer and that use of multiple vitamins containing folic acid reduces the risk of these cancers Findings relating folic acid intake to CVD and some cancers have major implications for many parts of the formulating world. In many areas, consumption of fruits and vegetables is low. For example, in northern China, approximately half the adult population is deficient in folic acid Consume cereal products in their whole-grain, high-fibre form. Consuming grains in a whole-grain, high-fibre form has double benefits. First, consumption of fibre from cereal products has consistently been associated with lower risks of CAD and type 2 diabetes which may be because of both the fibre itself and the vitamins and minerals naturally present in whole grains [13]. Given the importance of obesity and overweight in the causation of many chronic diseases, avoiding excessive consumption of energy from any source is fundamentally important. The principle justification for limiting sodium is its effect on blood pressure, a major risk factor for stroke and coronary disease WHO has suggested an upper limit of 1.7 grams of sodium per day (5 grams of salt per day) (A.H.A, 2017).

The word Cancer is a broad term referring to a class of diseases characterized by abnormal cells growths that invade healthy cells in the body [2]. Breast cancer for instance, starts in the cells of the breast as a group of cancer cells that can then invade surrounding tissues or spread (metastasize) to other areas of the body just like prostate cancer starts at the abdominal region of the body and later metastasize to other parts of the body (Elisa P, et al. 2014). What Causes Cancer to Formulate is the abnormality in cell development in the body: Cancer begins in the cells which are the basic building blocks that make up tissue (Boshra v, and Tajul AY 2013). These tissues are found in the breast, prostate and other parts of the body (Peter Crosta, 2015). Sometimes, the process of cell growth goes wrong and new cells form when the body doesn't need them and old or damaged cells do not die as they should (Elisa P, et al. 2014). When this occurs, a build up of cells often forms a mass of tissue called a lump, growth, or tumour (Boshra v, and Tajul A.Y, 2013). Breast cancer for instance, occurs when malignant tumours formulate in the breast just like prostrates cancer occurs around the abdominal region of the human body by the formation of malignant growth [2]. These cells can spread by breaking away from the original tumour and entering blood vessels or lymph vessels, which branch or spread into tissues throughout the body. When cancer cells travel to other parts of the body and begin damaging other tissues and organs, the process is called metastasis [2].

Cancer as an abnormal health condition remains one of the leading causes of morbidity and mortality in the entire universe [10]. Cancer is the second leading cause of death amongst the non-communicable diseases after cardiovascular disease being the first. Chemotherapy is routinely used for cancer treatment. Since cancer cells lose many of the regulatory functions present in normal cells, they continue to divide when normal cells do not. This feature makes cancer cells susceptible to chemotherapeutic drugs. Approximately five decades of systemic drug discovery and development have resulted in the establishment of a large collection of useful chemotherapeutic agents (I.N.D.S.; 2013).

Diabetes is defined as an abnormal health condition that is caused by impaired insulin and Leptin sensitivity (N.D.I.C., 2017). It is also commonly believed by many professionals and highly respected medical practitioners 'that this health condition is caused by excess sugar or glucose in the blood and that is the major reason it is often called high blood sugar. In simple terms, diabetes is an abnormality that means having excess glucose or sugar in the blood (N.D.I.C., 2017). Even though your blood actually needs some amount of glucose for energy supply to keep you strong, too much of it could be disastrous to your health. Glucose comes from the food human ingest into their body, from the liver and also from our muscles. The blood then carries the same glucose into all parts (cells) of the body. Insulin is a chemical or hormone secreted or produced by the pancreas into the blood which controls the rate at which glucose gets into the body cells (N.D.I.C., 2017). If your system does not have enough insulin required for controlling this processes, or if the available insulin does not work optimally as expected, then the glucose will not get into your body cells. Instead, it will remain in your blood cells rather accumulating. Eventually, it will becomes high and at this stage it is said "you have high blood sugar" or diabetes (N.D.I.C., 2017).

Blood pressure is the measure of the force of blood pushing against blood vessel walls (Ranilla, L.G. et al.;2010). The heart pumps blood into the arteries (blood vessels), which carry the blood throughout the body (Faral-Tello P, et al. 2012). High blood pressure, also called hypertension, is dangerous because it overwork the heart by pumping blood 


\section{Current Research in Diabetes \& Obesity Journal}

harder to the body and contributes to hardening of the arteries, or atherosclerosis, to stroke, kidney disease, and to the development of other cardiovascular diseases (Faral-Tello P, et al. 2012). Blood pressure is a ratio ideally, we should all have a blood pressure below 120 over 80 (120/80) (Faral-Tello P, et al. 2012). This is the ideal blood pressure for people wishing to have good health. At this level, we have a much lower risk of heart diseases or stroke (Alina Brandford, 2016). This blood pressure level is what is called optimal or normal blood pressure level (Amin Z A, et al. 2012).

Blood pressure reading has a top number called systolic and bottom number called diastolic. The ranges are: Normal: Less than 120 over 80 (120/80) Pre-hypertension: 120-139 over 8089 is called Stage 1 high blood pressure: $140-159$ over $90-99$ is called Stage 2 high blood pressure: 160 and above over 100 and above and High blood pressure in people over age 60: 150 and above over 90 and above (Dominic SJ, et al. 2008). The real causes of high blood pressure are not accurately known, it is attributed to several factors which includes: Smoking, excess alcohol consumption, stress, older age, genetics and or family history Yang JW et al. (2016).

A Stroke is consequential results of A cardiovascular disorder especially hypertension which occurs when the blood supply to the brain is interrupted or reduced [7]. When this happened, it deprives the brain of oxygen and nutrients, which are capable of causing the brain cells to die. A stroke may be caused by a blocked artery and it is called ischemic stroke or by the leaking or bursting of a blood vessel and is called hemorrhagic stroke while some people may experience only a temporary disruption of blood flow to their brain and this type of stroke is called transient ischemic attack (TIA) The signs and symptoms of strokes are: Having trouble with speaking and understanding Gomes JE et al. (2013). You may experience confusion.

You may slur your words or have difficulty understanding speech, Having Paralysis or numbness of parts of your body like; the face, arm or leg, Formulating sudden numbness, weakness or paralysis especially on one side of your body, If one of your arm begins to fall when you Try to raise both your arms over your head at the same time, you may be having a stroke A.C.B.C.C.; (2010). Similarly, one side of your mouth may droop when you try to smile, Having Trouble with seeing in one or both eyes. You may suddenly have blurred or blackened vision in one or both eyes, and you may see double, having Headache. A sudden, severe headache, which may be accompanied by vomiting, dizziness or altered consciousness, may indicate you're having a stroke, Having Trouble with walking. You may stumble or experience sudden dizziness, loss of balance or loss of coordination [7].

\section{Materials and Methods}

\section{Materials}

The facilities of Minna, Suleja and Sabontasha General Hospitals were major contact points and individuals homes a rounds this vicinities in the two state of Niger and Kaduna both in Northern Nigeria.

\section{Methods of Data Collection}

\section{Survey method of data collection:}

i. Survey for cancer risks factors: The survey on cancer risks factors (RFs) was carried out using Minna (especially Raised foundation, Reproductive rights advocacy, safe spaces and empowerment cancer screening centre Okada road Minna), Minna general Hospital, suleja general hospital and Sabontasha general Hospital Kaduna state.

ii. Survey for diabetes risks factors (RF's): The survey for Diabetes risks factor was carried out using Minna especially the general hospital, Suleja especially the general hospital in Niger State and Sabontasha general hospital and Kajuru town in Kaduna state as case study.

\section{Survey on Risks Factors of Hypertension/High blood pressure and stroke}

Survey on risks factors of blood pressure was carried out using Minna (especially the general hospital), suleja (especially the general hospital), Sabontasha and Kajuru as case study. The Survey on risks factors of stroke was carried out at the same areas as those in diabetes and blood pressure $[14,15]$. For diabetes and hypertension, two hundred people were involved minimum (lower limit) age of 18 years while the highest age range for each was only determined by the oldest person who fill the questionnaire. For cancer and stroke the target subjects of survey were people of at least 30 years (lower limit) and the upper limit was determined after the collation of the survey results and seeing the highest age limits. Some who could not write were granted interviews and their questionnaires filled, while those who can write filled the questionnaires themselves [16]. The general hospitals and cancer centres were focal points for the search for data from individuals even though not limited to those places. For the four diseases, cancer, diabetes, blood pressure and stroke.

\section{Results and Discussions}

\section{Survey results on risks factors of diabetes, blood pressure, stroke and cancer}

\section{Survey result on diabetes risks factors (RF's) and their discussions}

The risks factors that were of interest are: smoking, obesity, family history, drinking of alcohols, insulin resistance, physical exercise, impaired glucose tolerance, disease of the pancreas, persistence injury and the eating of refined sugar keeping age ranges from eighteen years and above [17]. The result as shown above, demonstrate high impacts of life style on an individual in terms of becoming diabetic, managing it or avoiding its occurrence in the first instance.

(Table 1) The result of the survey on physical exercise for example show that out of the two hundreds peoples that were granted interviews, only 45 persons exercise, while 86 indicated that they do not and 69 people were doing before but have stopped [18]. and reduction in obesity play vital roles in prevention of diabetes and management of the disease when it occurs 101 


\section{Current Research in Diabetes \& Obesity Journal}

person have BMI greater than $23 \mathrm{~kg} / \mathrm{m}^{2}$ which indicate tendency of diabetes. According to the above survey findings, there is a linear relationship between life style and diabetes mellitus. Regular physical exercise has been known to be beneficial in the prevention and treatment of type 2 diabetes and sometimes in the management of type 1 diabetes [19]. According to the result obtained and interaction with those who were in emergency case of diabetes mellitus, immediately they came of their emergency cases, and adjust their lives style, the glycemic/ glucose level drop to acceptable range of less than $100 \mathrm{mg} / \mathrm{dL}$.

Table 1: Shows survey result on risks factors (RF's) of Diabetes Mellitus.

\begin{tabular}{|c|c|c|c|c|c|c|c|c|c|c|}
\hline $\begin{array}{c}\text { Risks Factors (RF's) } \\
\text { of Diabetes }\end{array}$ & Yes & No & Before & $\begin{array}{c}\text { Age } \\
\text { Range }\end{array}$ & Male & Female & $\begin{array}{c}\text { Type 1 } \\
\text { diabetes }\end{array}$ & $\begin{array}{c}\text { Type 2 } \\
\text { diabetes }\end{array}$ & $\begin{array}{c}\text { Gestational } \\
\text { Diabetes }\end{array}$ & $\begin{array}{c}\text { I do know } \\
\text { Diabetic }\end{array}$ \\
\hline Smoking & 27 & 141 & 32 & $18-97$ & 100 & 100 & 8 & 42 & 29 & 58 \\
\hline $\begin{array}{c}\text { Obesity/Overweight } \\
\text { (BMI> 23 }\end{array}$ & 101 & 47 & 52 & $18-97$ & 100 & 100 & 8 & 42 & 29 \\
\hline Family History & 68 & 132 & - & $18-97$ & 100 & 100 & 8 & 42 & 29 & 58 \\
\hline Drinking of Alcohols & 52 & 120 & 2 & $18-97$ & 100 & 100 & 8 & 42 & 29 & 58 \\
\hline Insulin Resistance & 53 & 147 & - & $18-97$ & 100 & 100 & 8 & 42 & 29 & 58 \\
\hline Physical Exercise & 45 & 86 & 69 & $18-97$ & 100 & 100 & 8 & 42 & 29 & 58 \\
\hline $\begin{array}{c}\text { Impaired Glucose } \\
\text { Tolerance }\end{array}$ & 41 & 147 & 12 & $18-97$ & 100 & 100 & 8 & 42 & 29 \\
\hline $\begin{array}{c}\text { Disease of the Pan- } \\
\text { creas }\end{array}$ & 3 & 197 & - & $18-97$ & 100 & 100 & 8 & 42 & 58 \\
\hline Infection or Illness & 89 & 54 & 57 & $18-97$ & 100 & 100 & 8 & 42 & 29 \\
\hline Eating Refined Sugar & 175 & 10 & 15 & $18-97$ & 100 & 100 & 8 & 42 & 29 \\
\hline
\end{tabular}

Those with type 1 diabetes who combine healthy feeding habits, exercised, and abstinence from alcoholism, smoking, obesity said: they have been able to manage the disease effectively without suffering from most of the complications that are associated with it [20]. That is, other cardiovascular failures. this agrees with Epidemiological studies of physical exercise: previous non-randomized studies suggested that a life-style intervention program involving diet and/or exercise reduced the progression of impaired glucose tolerance (IGT) to type 2 diabetes and managed effectively type one diabetes and gestational diabetes as well [21]. Recent randomized controlled intervention trials also showed that diet and/or exercise intervention led to a significant decrease in the incidence of diabetes among those with Impaired Glucose Tolerance which completely agreed with the findings of this survey [22]. View from Endocrinological and metabolic effects of exercise: in well controlled diabetic patients, physical exercise is said to promote effective utilization of blood glucose and lowers blood glucose levels which if continued leads to a life time freedom from the impaired condition and these also agrees with the response of victims during this interaction [23].

According to research, Long-term gentle regular jogging increases insulin action in respect of both carbohydrate and lipid metabolism despite no influence on body mass index or maximal oxygen uptake. Observations have shown a significant correlation between insulin sensitivity and average daily steps [24]. According to recent findings, the improvement of insulin action by physical exercise was attributed, at least in part, to the increase in insulin-sensitive of glucose transporter on the plasma membrane in skeletal muscle. Physical activity is recognized to produce multiple general and diabetes-specific health benefits.
Those who violate the instruction of restricted feeding counted their pains as the level will suddenly shoot up. Yet despite the multitude of benefits, it has been discovered that many people are physically inactive. The results also show a corresponding relationship between diabetes, high blood pressure and stroke.

The results also showed that younger people affected by diabetes, suffers from type one diabetes, and have family history of diabetes [25]. Majority of those who indicated that they have type 2 diabetes, are people from the ages of 40 to the 97 years according to the survey. A total of 8 people indicated type 1 diabetes, 42 persons indicated type 2 diabetes and 29 persons shows that they have gestational diabetes. 63 people say they do not know while 58 said they have tested and they do not have diabetes. Age has been used by many shown to be one of the major risks factors of diabetes apart from obesity, the results shows very similar trend, but have been interpreted otherwise: It is the residual effects of other adjustable factors that have predisposes age as a major risks factor. Some people above eighty indicated that they were free from diabetes, while many far below that were diabetic [26]. The reason was that this same people indicated very high sense of discipline in terms of their life style while others were just taking anything that come their way and living care free life.

In order to reduce the incidences of cardiovascular diseases, in the world of today and thus minimizing the individual, familial, and public health burden, diabetes must be prevented or at worst, manage well. Low glycemic index dietary patterns reduce both fasting blood glucose and glycated proteins independent of carbohydrate consumption [27]. Diets rich in whole-grain, cereal high fibre products, and non-oil are very good for this purpose. Obesity is the most important factor accounting for more than half 


\section{Current Research in Diabetes \& Obesity Journal}

of new diabetes' cases while modest weight loss has a favourable effect in preventing the appearance of diabetes, blood pressure and stroke. Also, physical exercise with or without diet contributes to a healthier lifestyle and is important for lowering the risks of these diseases $[28,29]$.

\section{Survey Results on Risks Factors of Hypertension and their Discussions}

(Table 2) The following were the risks factors of interest: diabetes, high blood pressure, heart diseases, smoking, obesity, family history and arteriovenous Malfunctions. Out of the 200 people granted interview, ranging from age 18-98, a total of 67 people indicated been diabetic, 95 indicated they are not diabetic while 38 people say they were before, but since, they adjusted their life style earlier, they have been free since then. A total of 74 persons indicated being hypertensive, 76 indicated not been hypertensive while fifty indicated that they were also hypertensive but having adjusted their life style earlier, they are managing it effectively. Heart diseases 39 indicated heart disease specifically breathe seizure intermittently, 125 people say they do not have such diseases while 36 indicated that they were suffering from it before now but it has been treated with the helped of their life style modification. 27 indicate that they smoke, 141 indicated that they do not smoke while 32 people indicated that they have smoked before [30]. 98 people indicated been obese, 47 not obese while 52 people indicated being obese before now. 76 people indicated they have family history of stoke while 124 people indicated that there is no such history in their family. 15 people indicated having brain malfunction while 185 people indicated free from it. Out of this people 15 indicated hemorrhagic stroke through their relatives 23 indicted being victims of transients' ischemic stroke, 37 ticked transient ischemic attack, 41 people say, they do not know while 84 people indicated that they are not affected at all [31].

Table 2: Shows survey results on risks factors (RF's) of hypertension.

\begin{tabular}{|c|c|c|c|c|c|c|c|c|c|c|}
\hline $\begin{array}{l}\text { Risks Factors Of Hy- } \\
\text { pertensions (HHT) }\end{array}$ & Yes & No & Before & $\begin{array}{l}\text { Age } \\
\text { Range }\end{array}$ & Male & Female & $\begin{array}{c}\text { Essential } \\
\text { Hyperten- } \\
\text { sion }\end{array}$ & $\begin{array}{c}\text { Secondary } \\
\text { Hypertension }\end{array}$ & $\begin{array}{l}\text { I do not } \\
\text { know }\end{array}$ & $\begin{array}{c}\text { I am not Hyper- } \\
\text { tensive }\end{array}$ \\
\hline Family History & 68 & 132 & - & $18-99$ & 100 & 100 & 12 & 28 & 67 & 93 \\
\hline Obesity or & 71 & 87 & 42 & $18-99$ & 100 & 100 & 12 & 28 & 67 & 93 \\
\hline Physical Exercise & 45 & 86 & 69 & $18-99$ & 100 & 100 & 12 & 28 & 67 & 93 \\
\hline Smoking & 27 & 141 & 32 & $18-99$ & 100 & 100 & 12 & 28 & 67 & 93 \\
\hline Excess Sodium & 123 & 57 & 20 & $18-99$ & 100 & 100 & 12 & 28 & 67 & 93 \\
\hline Little Potassium & 98 & 96 & 6 & $18-99$ & 100 & 100 & 12 & 28 & 67 & 93 \\
\hline Diabetic & 57 & 153 & - & $18-99$ & 100 & 100 & 12 & 28 & 67 & 93 \\
\hline
\end{tabular}

Comparing literature and the findings of this research, many stroke risk factors are lifestyle related. Furthermore, the risk of a stroke is said to be tenfold higher in someone who has had a stroke in the past," according to Larry B. Goldstein, MD, a professor of medicine (neurology) and director of the Duke Stroke Centre in Durham, N.C. he said: Prevention of a second stroke starts by addressing conditions that caused the first stroke, such as a trial fibrillation (an abnormal heart rhythm that can cause blood to clot) or narrowing of a carotid artery in the neck the above statement also means that, to prevent the occurrence of stoke, one need to make sure that established risk factors of stroke that are related to life style, are avoided completely if possible [32]. Treatment of stroke is also aimed at the factors that put one to the attach in the first place. Some stroke risk factors can't be controlled however research findings; have shown that most of those uncontrollable risk factors are still influenced by controllable ones. Hence, uncontrollable risk factors like gender, age and family history which in my view are dependent of the controllable ones, can be fixed if the controllable ones are fixed [33].

The result above shows that there is a direct relationship between strokes and these risks factors such as: high blood pressure, tobacco smoking, diabetes, high blood glucose levels, heavy drinking, a diet high in fat (particularly saturated fats) and salt or what is called sodium chloride [34]. Most people with stroke or history of stroke indicated that they were or currently victims of either of the above listed risks factors. The result of this survey show that those with stroke either partial or permanent had at one time or the other suffered from high blood pressure, and or diabetes. Some also indicated that they have smoked, and or engage in alcoholism in addition to these factors [35]. Also most of those who, lack regular exercise, obesity or with high body mass index (BMI) indicate that they have also suffered from stroke. The collection of some of these risks factors or all of them into one is what is refers to as absolute risk factor. Surviving a stroke can be a powerful motivation to make lasting positive changes in your life however most victims never had that privilege to tell their story.

\section{Survey results on cancer risks factors (RF's) and their discussion}

(Table 3) The factors of interest are: hash radiation, use of hard drugs, family history, smoking, drinking, alcohol, harsh chemicals and obesity. From the total 200 people granted interview, 57 persons indicated being exposed to harsh radiations, 98, say no while fourty five say before but they have stopped. 38 admitted the used of hard drugs, 140 indicated no while 22 say before. 30 indicated having family history while 170 indicated no family 


\section{Current Research in Diabetes \& Obesity Journal}

history.42 people indicated that they are smoking, 138 say no while only 20 said they smoked before. 57 accepted drinking alcohols 117 said they do not drink alcohol while 26 indicated that they use to drink before [36]. 61 say they are expose to hash chemicals, 97 indicated that they are not exposed to any while 42 said they were exposed to it before. 78 people said they are obese, 65said they are not while 57 said before but not anymore. Most people that indicated having are people with skin cancer (9 people), blood cancer ( 2 people) prostate cancer (15 people), cervical cancer (17), gastrointestinal cancer (8 people), those who indicated that they do not know are (64 people) while those who say they are free from cancer are 84 people [37].

Table 3: Shows survey results on risk factors (RFs) of cancer.

\begin{tabular}{|c|c|c|c|c|c|c|c|c|c|c|c|c|c|}
\hline $\begin{array}{c}\text { Risks } \\
\text { factors of } \\
\text { Cancer }\end{array}$ & Yes & No & Before & $\begin{array}{c}\text { Age } \\
\text { Range }\end{array}$ & Male & Female & $\begin{array}{l}\text { Skin } \\
\text { Cancer }\end{array}$ & $\begin{array}{l}\text { Breast } \\
\text { Cancer }\end{array}$ & $\begin{array}{l}\text { Prostate } \\
\text { Cancer }\end{array}$ & $\begin{array}{l}\text { Cervical } \\
\text { Cancer }\end{array}$ & $\begin{array}{l}\text { Gastro intes- } \\
\text { tinal cancer }\end{array}$ & $\begin{array}{l}\text { I do not } \\
\text { know }\end{array}$ & $\begin{array}{c}\text { Not } \\
\text { affected }\end{array}$ \\
\hline $\begin{array}{l}\text { Harsh Radi- } \\
\text { ation }\end{array}$ & 57 & 98 & 45 & $30-89$ & 100 & 100 & 9 & 13 & 15 & 17 & 8 & 51 & 87 \\
\hline $\begin{array}{l}\text { Use of hard } \\
\text { drugs }\end{array}$ & 38 & 140 & 22 & $30-89$ & 100 & 100 & 9 & 13 & 15 & 17 & 8 & 51 & 87 \\
\hline $\begin{array}{l}\text { Family } \\
\text { history }\end{array}$ & 30 & 170 & - & $30-89$ & 100 & 100 & 9 & 13 & 15 & 17 & 8 & 51 & 87 \\
\hline Smoking & 42 & 138 & 20 & $30-89$ & 100 & 100 & 9 & 13 & 15 & 17 & 8 & 51 & 87 \\
\hline $\begin{array}{l}\text { Drinking } \\
\text { Alcohols }\end{array}$ & 57 & 117 & 26 & $30-89$ & 100 & 100 & 9 & 13 & 15 & 17 & 8 & 51 & 87 \\
\hline $\begin{array}{c}\text { Harsh } \\
\text { chemicals }\end{array}$ & 61 & 97 & 42 & $30-89$ & 100 & 100 & 9 & 13 & 15 & 17 & 8 & 51 & 87 \\
\hline Obesity & 78 & 65 & 57 & $30-89$ & 100 & 100 & 9 & 13 & 15 & 17 & 8 & 51 & 87 \\
\hline
\end{tabular}

From the survey results, must people who indicated that they are suffering from cancer, are people from Abuja screening centres and Amina Abubakar's screening centre minna. Most of them share their experiences as being suspecting infections which come with bleeding while others recount how hard drugs and smoking has ruins their lives. Some especial men and women suffering from prostrate and cervical cancer, say they were using sexual stimulants and continues family planning drugs. Breast cancer some also. Most it is however, very important to know that these risk factors as indicated, can contribute immensely to either make one highly prone to cancer invasion or secured completely from its invasion depending on your approach either to actively maintain a healthy life or mare it. Reports of clinical findings from different areas have also shown a linear relationship between all kinds of cancers and one or all of the following risk factors (RFs): alcoholism, all kinds of smoking, obesity (high BMI), exposure to all kinds of harsh radiations, and or complicated infections. Such research also indicated the inverse relation between such risk factors (RFs) when life styles were modified in favour of a sound and healthy life. Exposure to excessive sun light results to skin cancer, obesity mostly results to abdominal (prostate/cervical cancer) cancer the use of harsh chemicals causes all kinds of cancers depending on their sites of effect. All kinds of radiations can cause mutation and consequently different kinds of cancers, alcoholism, and smoking can cause gastrointestinal cancers. Hence to prevent the occurrence of these deadly diseases, it is very important for one to avoid exposure to these risks factors. This is because, life style does not only influence our day to day but also have lasting effects in our lives.

\section{Conclusion}

Hence, no matter your age, sex, origin or race; to have good health status and optimum result from taking whatever types of medication including this multifunctional flora composite (bioactivator), and any other green medicine in case you become ill, one need to combine it with life style modification or adjustment of life style depending risks factors of such diseases to suit good health conditions. in other words, to prevent the occurrence of cancer or manage it in case it occurs, one need to observed the following life style: do not smoke, do not drink alcohol, do not expose yourself to harsh radiation, do not eat bad food or chemically treated food, live in a sanitised and health friendly environment in addition to taking supplements like this multifunctional flora composite regardless of your age, gender, ethnicity, or family history. Also, to prevent the occurrence of diabetes or manage it when it occurs, one need to observe the following life style: avoid fatty and sugary food, monitor your weight (body mass index), do a lot of exercise, avoid the occurrence of autoantibody.

No matter your age, sex, family history, or ethnicity combines with this multifunctional floral composite. For blood pressure, one needs to: do not be overweight or obese, be physically very active/ exercise, avoid the use of tobacco and do not smoke, do not use too much sodium but take enough potassium to balance your sodium intake, do not drink alcohol, avoid unnecessary stress, avoid things that will lead to diabetes or kidney diseases in addition to this flora composite, no matter the sex, age, ethnicity, or family history. Finally to prevent stroke or manage it when it occurs, one needs to: avoids things that lead to diabetes, blood pressure, or 


\section{Current Research in Diabetes \& Obesity Journal}

any other heart disease. Do not smoke, dot not take alcohol, avoid arteriovenous malformations nor matter your age, Gender, race, ethnicity or family history. In a nutshell life style modification and maintenance of good health habits give greater results that the best corrective and curative drug anyone could ever discover.

\section{References}

1. Tahiya Hilal Ali Alabri, Amira Hamood SalimAl Musalami, Mohammad Amzad Hossain, Afaf Mohammed Weli, Qasim Al-Riyami (2013) Comparative study of phytochemical screening, antioxidant and antimicrobial capacities of fresh and dry leaves crude plant extracts of Datura metel L. Journal of King Saud University 26(3): 237-243.

2. Asish Bhaumik, Swapna M, Sucharitha M, Devika K, Ashwini Kumari N (2015) The Bioactive Compounds obtained from the Papaya (Carica Papaya) act as potential Anticancer agents against the human prostate Cancer Cell Line du-145. International Journal of Pharmacy \& BioSciences 2(1): 1-5.

3. World Health Organization (W.H.O) (2010) Guidelines for the treatment of malaria, $\left(2^{\text {nd }} E d n\right)$, Geneva, Switzerland.

4. World Health Organization (2012) Management of severe malaria: a practical handbook, ( $3^{\text {rd }}$ Edn), Geneva, Switzerland.

5. Aravind G, Debjit Bhowmik, Duraivel S, Harish G (2013) Traditional and Medicinal Uses of Carica papaya. Journal of Medicinal Plants Studies 1(1): 7-15.

6. Gomes J, Wachsman AM Corrigan ML (2013) Types of strokes, Handbook of Clinical Nutrition and Stroke, Nutrition and Health, Springer Science and Business Media, New York, USA.

7. American Stroke Association (A.S.A) (2017) Together to end stroke.

8. Peter Crosta (2015) Cancer: Facts, Causes, Symptoms and Research, Medical News Today knowledge center home cancer facts, causes and research.

9. American Stroke Association (2017) What is stroke, American Stroke Association.

10. Avni G Desai, Ghulam N Qazi, Ramesh K Ganju, Mahmoud El-Tamer Jaswant Singh (2008) Medicinal Plants and Cancer Chemoprevention. Curr Drug Metab 9(7): 581-591.

11. Oseni Kadiri, Babatunde Olawoye, Olumide S Fawale, Olusoji Adeola Adalumo (2016) Nutraceutical and Antioxidant Properties of the Seeds, Leaves and Fruits of Carica papaya: Potential Relevance to Humans Diet, the Food Industry and the Pharmaceutical Industry-A Review. Turkish Journal of Agriculture-Food Science and Technology 4(12): 1039-1052.

12. CDC (2013) Treatment of Malaria (Guidelines For Clinicians) Centers For Disease Control And Prevention. 1-8.

13. Daniele Del Rio, Ana Rodriguez-Mateos, Jeremy PE Spencer, Massimiliano Tognolini, Gina Borges, et al. (2013) Dietary (Poly) phenolic in Human Health: Structures, Bioavailability, and Evidence of Protective Effects against Chronic Diseases. Antioxid Redox Signal 18(14): 1818-1892.

14. Satya Prakash Mishra, Pankaj Singh, Sanjay Singh (2012) Processing of Moringa oleifera Leaves for Human Consumption. Bulletin of Environment, Pharmacology and Life Sciences 2 (1): 28-31.

15. National Heart, Lung and Blood Institutes of Health (2013) U.S. Department of Health \& Human Services.

16. Paul SH, Adeniyi OD, Olutoye MA (2017) Production and Characterization of Soymilk Using Locally Prepared Date Paste (Phoenix Dactylifera), White Sugar and Glycerol as Sweeteners. Current Trends in Biomedical Engineering \& Biosciences 7(2): 555709.

17. United State Department of Health and Human Services (2003) National Cancer Institute, What You Need to Know What You Can
Do, National Institutes of Health National Cancer Institute National Institute of Environmental Health Sciences, CANCER AND THE ENVIRONMENT

18. Paul SH, Usman AA, Adeniyi OD, Olutoye MA (2017) Production and Application of Moringa-Aluminates for Water Treatment as a Facile Biochemical Coagulant. Current Trends Biomedical Engineering \& Biosciences 3(5): 555622.

19. World Health Organisation W.H.O (2009) Cancer and how to fight it.

20. The Agency for Toxic Substances and Disease Registry (T.A.T.S.D.R.) (2014) Chemicals, Cancer, and You, based in Atlanta, Georgia, is a federal public health agency of the US Department of Health and Human Services, Division of Health Assessment and Consultation.

21. International Agency for Research on Cancer (I.A.F.R.C.) (2017) Environmental Causes of Cancer.

22. National Cancer Institute (2003) What You Need to Know What You Can Do, U.S. DEPARTMENT OF HEALTH AND HUMAN SERVICES, National Institutes of Health National Cancer Institute National Institute of Environmental Health Sciences, CANCER AND THE ENVIRONMENT.

23. National Institutes of Diabetes, Digestive and Kidney Disease (2015) NIH U.S. Department of Health and Human Services National Institutes of Health USA.gov.

24.World Health Organization, WHO, November (2010), Diabetes, Diabetes Fact Sheet. Diabetes Atlas, 4th edition, International Diabetes Federation, 2009.

25. Khalil MI, Sulaiman SA (2010) The Potential Role of Honey and its Polyphenols in Preventing Heart Diseases: A Review African Journals of Traditional Complement Alternative Medicines 7(4): 315-321.

26. Usunobun Usunomena (2012) Review Manuscript: A Review of Some African Medicinal Plants. Journal of Pharmacy and Biomedical Sciences 3(4): 1-11.

27. Centre for Chronic Disease Control (2009) KNOW THE FACTS ABOUT Stroke, National Centre for Chronic Disease Prevention and Health Promotion Division for Heart Disease and Stroke Prevention Deaths: Final Data for 2009.

28. Louis H Miller, Michael F Good, Genevieve Milon (1999) Definition, Diagnosis and Classification of Diabetes Mellitus and its Complications, Report of a WHO Consultation, Part 1: Diagnosis and Classification of Diabetes Mellitus, WHO/NCD/NCS/99.2 Original: English Distribution: General @ World Health Organization 1999, World Health Organization Department of Non communicable Disease Surveillance, Geneva Malaria Pathogenesis

29. Heart Disease and Stroke Statistics (2013) KNOW THE FACTS ABOUT Stroke Update. National Centre for Chronic Disease Prevention and Health Promotion Division for Heart Disease and Stroke Prevention.

30. National Institute for Communicable Diseases (NICD) (2016) Typhoid: NICD recommendations for diagnosis, management and public health response, Version 2, Unit Guidelines typhoid 20160125, page 1-15 Updated by: The Outbreak Response Units and the Centre for Enteric Diseases of The National Institute for Communicable Diseases (NICD), a division of the National Health Laboratory Service (NHLS).

31. Filio Marineli, Gregory Tsoucalas, Marianna Karamanou, George Androutsos (2013) Mary Mallon and the history of typhoid fever, HISTORY IN GASTROENTEROLOGY, Annals of Gastroenterology 26: $1-3$

32. I.N.D.I., (2013) (Irish Nutritional and Dietetic Institute).

33. Akhila S, Vijayalakshmi NG (2015) Phytochemical Studies on Carica Papaya Leaf Juice. International Journal of Pharmaceutical Sciences and Research 6(2): 880-883.

34. Kathi J Kemper (1999) The Centre for Holistic Pediatric Education and Research (Zingiber officinale). 


\section{Current Research in Diabetes \& Obesity Journal}

35. Heart Diseases and Stroke Prevention (2017) KNOW THE FACTS ABOUT Stroke, Centres for Disease Control and Prevention's Division for Heart Disease and Stroke Prevention.

36. Jaleel Kizhakkayil, Sasikumar B (2012) Characterization of ginger (Zingiber officinale Rosc.) germplasm based on volatile and nonvolatile components. African Journal of Biotechnology 11(4): 777-786.
37. Prashant Tiwari, Bimlesh Kumar, Mandeep Kaur, Gurpreet Kaur, Harleen Kaur (2011) Phytochemical screening and Extraction: A Review, Internationale Pharmaceuticasciencia 1 (1)

Your next Submission with Juniper Publishers
will reach you the below assets
- Quality Editorial service
- Swift Peer Review
- Reprints availability
- E-prints Service
- Manuscript Podcast for convenient understanding
- Global attainment for your research
- Manuscript accessibility in different formats
( Pdf, E-pub, Full Text, Audio)
- Unceasing customer service
Track the below URL for one-step submission
https://juniperpublishers.com/online-submission.php

